\title{
Indigenous house mice dominate small mammal communities in northern Afghan military bases
}

Christoph Gertler ${ }^{1,11}$, Mathias Schlegel ${ }^{1,12}$, Miriam Linnenbrink2 ${ }^{2}$, Rainer Hutterer ${ }^{3}$, Patricia König ${ }^{4}$, Bernhard Ehlers ${ }^{5}$, Kerstin Fischer ${ }^{1}$, René Ryll ${ }^{1}$, Jens Lewitzki ${ }^{6}$, Sabine Sauer ${ }^{7}$, Kathrin Baumann $^{1}$, Angele Breithaupt ${ }^{8}$, Michael Faulde ${ }^{9}$, Jens P. Teifke ${ }^{8}$, Diethard Tautz ${ }^{2}$ and Rainer G. Ulrich ${ }^{1,10^{*}}$

\begin{abstract}
Background: Small mammals are important reservoirs for pathogens in military conflicts and peacekeeping operations all over the world. This study investigates the rodent communities in three military bases in Northern Afghanistan. Small mammals were collected in this conflict zone as part of Army pest control measures from 2009 to 2012 and identified phenotypically as well as by molecular biological methods.

Results: The analysis of the collected small mammals showed that their communities are heavily dominated by the house mouse Mus musculus and to a lesser extent Cricetulus migratorius and Meriones libycus. The origin of M. musculus specimens was analyzed by DNA sequencing of the mitochondrial cytochrome $b$ gene and D-loop sequences. All animals tested belonged to the Mus musculus musculus subspecies indigenous to Afghanistan. The results were supported by detection of two nucleotide exchanges in the DNA polymerase gene of Mus musculus Rhadinovirus 1 (MmusRHV1), a herpesvirus, which is specific for all gene sequences from Afghan house mice, but absent in the MmusRHV1 sequences of German and British house mice. Studies of astrovirus RNA polymerase gene sequences did not yield sufficient resolution power for a similarly conclusive result.
\end{abstract}

Conclusions: House mouse populations in military camps in Northern Afghanistan are indigenous and have not been imported from Europe. Nucleotide sequence polymorphisms in MmusRHV1 DNA polymerase gene might be used as an additional phylogeographic marker for house mice.

Keywords: Military bases, Rodent, Shrew, Mus musculus, Phylogeography, Viruses, Public health, Afghanistan, ISAF, One health, Invasive species

\section{Background}

Modern warfare in the early $20^{\text {st }}$ century is characterized by peacekeeping operations as well as counterinsurgency warfare [1]. Despite the advancements of logistics, medical support and technology, hygienic conditions in military bases in the Central Asian theatre or in Forward Operating Bases (FOBs) used for combat operations, still may support the spread of infectious

\footnotetext{
* Correspondence: rainer.ulrich@fli.de

${ }^{1}$ Friedrich-Loeffler-Institut, Federal Research Institute for Animal Health, Institute of Novel and Emerging Infectious Diseases, Greifswald-Insel Riems, Greifswald, Germany

${ }^{10}$ German Center for Infection Research (DZIF), Partner Site

Hamburg-Luebeck-Borstel-Insel Riems, Greifswald-Insel Riems, Greifswald, Germany Full list of author information is available at the end of the article
}

agents [2-5]. Especially arthropod- or rodent-borne pathogens still pose a significant threat. Many of the current UN peacekeeping missions are located in areas that pose an infection risk with tropical viral, bacterial or protozoan pathogens [2-8]. The largest military operation of the last decade involving international personnel was the International Security Assistance Force (ISAF) in Afghanistan which started in December 2001. At the beginning of this study, it involved 56,420 military personnel from 50 countries in more than 700 military bases all over the country $[1,8,9]$. One of the largest bases in Northern Afghanistan was Camp Marmal near Mazar-e-Sharif, Balkh Province, Northern Afghanistan. The base did cater for up to 5500 military and non-military personnel from 16 countries. 
Camp Marmal was set up as a Forward Support Base (FSB) and was extended to serve as a transportation hub for up to 112,000 personnel and 28,000 tons of supplies per year at peak times from 2005 to 2009. It was connected to the surrounding provinces via five stationary Provincial Reconstruction Teams (PRTs) and additional FOBs, built up temporarily if operationally needed [1]. Due to the large quantities of personnel and goods transported through Camp Marmal as well as the garrison size of this installation, it was an excellent habitat for rodents that may carry arthropod vectors and /or zoonotic pathogens.

Northern Afghanistan is an endemic region for a large variety of human pathogens that may be carried by rodents or arthropod vectors, e.g. Salmonella typhi, S. typhimurium, Rickettsia spp., Leptospira spp., Coxiella burnetii, Leishmania spp., Giardia spp., Plasmodium spp. as well as Crimean-Congo hemorrhagic fever virus and West Nile virus [2]. A major outbreak of a zoonotic disease occurred in the Camp Marmal area between 2004 and 2006. More than 4200 cases of Zoonotic Cutaneous Leishmaniasis (ZCL) were recorded within the local Afghan population and occurred mostly from August to November of every year within this period [3]. ISAF personnel were also affected with more than $200 \mathrm{ZCL}$ cases diagnosed between 2004 and 2005 [4]. To prevent further infections of ISAF as well as employed civil personnel with Leishmania spp., a parasite with a rodent reservoir host, both major reconstruction works and pest control operations have been conducted throughout the further operation time of Camp Marmal [5] by a dedicated pest control unit. As Afghanistan is home to a wide range of rodents which may harbor pathogens $[10,11]$, a seasonal monitoring for rodents and mosquitos was implemented to verify the effectiveness of used pest control measures and to reassess the risk of infectious diseases present inside military camps of German responsibility. In addition to Camp Marmal, pest control measurements were set in place at the PRTs Kunduz and Fayzabad as well as inside smaller FOBs if feasible concerning the security situation.

Transmission of small mammal-borne pathogens within military bases such as Camp Marmal could take place through ubiquitous rodents found in almost any human settlement, such as Rattus spp. or Mus spp.. Most prominent within these genera is the house mouse Mus musculus, a highly mobile, omnivorous and oligotrophic commensal with birth rates of 5-10 litters and with an average of six to eight young per litter [12]. Because of these high birth rates, house mouse populations are characterized by a strong resilience towards predation and pest control measures. These animals are considered an invasive species especially on island locations and caused devastations to the biodiversity of New Zealand as well as several island ecosystems of the South Atlantic and Indian Oceans during European exploration in the $19^{\text {th }}$ century $[13,14]$. This may be due to quick genotypic and phenotypic adaptations (e.g. adaptation to local pathogens or the local climate and food spectrum) in relatively short periods of time after invading an island [15].

Personnel and goods were initially transported into Camp Marmal from Germany and other international locations primarily via air transport from Termez (Uzbekistan) or Kabul (Afghanistan) as well as by train especially during the initial work-up phase until 2009. Following the construction of a runway and throughout the collection time of this study, most goods were airlifted from Germany (Cologne Airport, Leipzig Airport) directly to Camp Marmal [1]. Although pest control measures were in place in Germany before loading, delays during consignment in Kabul or Termez and "stand stills" during train rides could not be avoided. Therefore, it cannot be excluded that commensalic rodents such as M. musculus were transferred into Camp Marmal within the actual cargo and subsequently carry pathogens into the country.

This study aims at analyzing the small mammal communities available during pest control in Camp Marmal and the PRT Kunduz and PRT Fayzabad bases within the Northern Afghan theatre of military operations. The three bases were chosen as collection sites as they were visited by the pest control unit of the German Army. Collections were conducted as regular as possible as permitted by the military situation and necessity for pest control. The small mammal communities were analyzed by both phenotype and several molecular biological methods such as PCR-based analysis of the mitochondrial cytochrome $b$ gene and D-loop region. Finally, we compared DNA polymerase $(D P O L)$ gene sequences of a herpesvirus, Mus musculus rhadinovirus 1 (MmusRHV1, a double stranded (ds) DNA virus) as well as RNAdependent RNA polymerase $(R d R p)$ gene sequences of murine astroviruses (single stranded (ss) RNA viruses) in M. musculus specimens collected at Camp Marmal in Afghanistan and several locations in Europe. In the absence of serious zoonotic viruses in the Afghan specimens, these viruses were selected to investigate their suitability as additional phylogeographic markers, as they were detected in a significant number of Afghan house mouse specimens, have a high host-specificity and low or lacking zoonotic potential.

\section{Methods}

Small mammal trapping and transfer procedures

Small mammal collections were conducted by a dedicated Army pest control team (Sanitäts-Hygiene-Trupp) 
if feasible concerning the security situation, as described before [16]. Briefly, a total of 751 small mammals were trapped using mouse and rat snap traps or collected as rodenticide-poisoned carcasses with a daily control of all sampling sites from January 2009 to October 2012 after the initial work-up of the three German Military Camps based on the implemented pest control management. Trapping sites were disseminated inside the camps with special focus on sites with reported or suggested occurrence of rodents as well as vulnerable places like kitchens or food storage facilities. The size and location of the trap used was based on apparent environmental factors, the local habitat and the knowledge of small mammal behavior as decided by veterinary personnel. For the collection site Hazrat-e Sultan, a statistically insignificant number of five animals were collected. For ten animals, no collection site could be determined during dissections. Hence, these 15 animals were omitted in the in-depth analysis of this study. All collected small mammals were registered by the veterinary medical staff of Bundeswehr, stored in aluminum containers at $-20{ }^{\circ} \mathrm{C}$ prior to transportation and dissection at the FriedrichLoeffler-Institut, Greifswald-Insel Riems, Germany. Dissections were conducted according to standardized protocols in a biosafety level 3 containment laboratory. Weight, length (body and tail) and sex of each specimen and number of embryos of pregnant females were determined for future analysis on their association with pathogen prevalence. The phenotypical identification of small mammal species was accompanied by photo documentation of each animal. Tissues were removed in specific order as described before [16], placed in $1.5 \mathrm{ml}$ reaction tubes and stored at $-20{ }^{\circ} \mathrm{C}$ until further experimentation. Control animals were selected to reflect the diversity of European house mice with specific regard to the presence of both Mus musculus domesticus in the Western part of Germany and Mus musculus musculus in the Eastern part of Germany. As airlifts to Afghanistan were conducted from both areas (Cologne airport and Leipzig airport), animals from Western Germany and North Western Czech Republic (representing the Central European M. m. musculus population) were selected. The trapping of control animals for astrovirus and herpesvirus investigations at five sites in Germany and one site in the United Kingdom have been reported previously $[13,17,18]$. As no morphological vouchers could be preserved in this study, some preliminary species identifications were based on the photographic documentation and comparisons with museum specimens.

Nucleic acid extraction, PCR amplification of cytochrome $b$ gene and DNA sequence analysis

Molecular species identification of small mammals was conducted with a modified protocol based on a method described before [19]. Briefly, frozen small mammal tail or ear pinna tissue was cut into slices of $0.5 \mathrm{~mm}$ by $0.5 \mathrm{~mm}$ with a sterile scalpel, transferred into a $1.5 \mathrm{ml}$ reaction tube and immersed in $300 \mu \mathrm{l}$ of tissue lysis buffer $(50 \mathrm{mM} \mathrm{KCl}, 10 \mathrm{mM}$ Tris- $\mathrm{HCl} \mathrm{pH} \mathrm{9.0,0.45 \%} \mathrm{(v/v)}$ Nonidet P40, 0.45\% (v/v) Tween 20 (Sigma-Aldrich, Munich, Germany)). Three microliters of a $10 \mathrm{mg} \mathrm{ml}^{-1}$ proteinase K (Sigma-Aldrich) solution were added and the reaction mixture was incubated over night at $56{ }^{\circ} \mathrm{C}$ with mixing intervals of $10 \mathrm{~s}$ and $1000 \mathrm{rpm}$ and pauses of 3 min in a thermomixer (Eppendorf, Hamburg, Germany). Residual tissue was pelleted by centrifugation at $16,000 \times \mathrm{g}$ for $1 \mathrm{~min}$ in a tabletop centrifuge (Eppendorf) and lysates were transferred to another reaction tube. Remaining proteinase $\mathrm{K}$ was inactivated by incubation at $95{ }^{\circ} \mathrm{C}$ for $10 \mathrm{~min}$. An additional tenfold dilution of each lysate was prepared in sterile water. Each $22.5 \mu \mathrm{l}$ of PCR master mix contained $17.65 \mu \mathrm{l}$ of sterile water, $2.5 \mu \mathrm{l}$ of $10 \times$ PCR buffer, $250 \mu \mathrm{M}$ of each dNTP, $1.5 \mathrm{mM}$ of $\mathrm{MgCl}_{2}$ (all Qiagen, Hilden, Germany), $200 \mathrm{nM}$ of each primer cytochrome bF (5`-TCA TCM TGA TGA AAY TTY GG-3`) and cytochrome b-R (5`-ACT GGY TGD CCB CCR ATT CA-3`) (MWG-Eurofins, Munich, Germany), and $0.1 \mu \mathrm{l}$ of Platinum Taq Polymerase (Life Technologies, Darmstadt, Germany). For each template, $2.5 \mu \mathrm{l}$ of undiluted extracts were applied in separate reactions. PCR reaction programs contained an initial denaturation step of $94{ }^{\circ} \mathrm{C}$ for $3 \mathrm{~min}$, followed by 40 cycles of $94{ }^{\circ} \mathrm{C}$ for $1 \mathrm{~min}, 53{ }^{\circ} \mathrm{C}$ for $30 \mathrm{~s}$ and $72{ }^{\circ} \mathrm{C}$ for $1 \mathrm{~min}$. A final elongation step was conducted at $72{ }^{\circ} \mathrm{C}$ for $10 \mathrm{~min}$. All PCR products were visualized on $1.5 \%$ agarose gels after electrophoresis at $100 \mathrm{~V}$ for $30 \mathrm{~min}$ and ethidium bromide staining on an INTAS Classic gel documentation system (INTAS, Göttingen, Germany). For all reactions that failed to amplify, tenfold diluted DNA extracts were used for an additional PCR amplification trial as described above. Due to poor cytochrome $b$ sequence quality in some Meriones specimens, the DNA extraction was repeated from kidney tissue using EURx GeneMATRIX Tissue DNA Purification Kit (Roboklon, Potsdam, Germany) and followed the protocol of the manufacturer. The PCR protocol presented above was modified by replacing buffer and polymerase by $5 \mu \mathrm{l}$ of Colorless GoTaq Flexi buffer (Promega, Mannheim, Germany) and $1 \mathrm{U}$ of GoTaq Polymerase (Promega) while reducing the amount of sterile water to $15.15 \mu \mathrm{l}$.

PCR products were purified with the Nucleospin kit (Macherey-Nagel, Düren, Germany). Sequencing reactions were performed using the ABI Big Dye v3.1 kit (Applied Biosystems, Foster City, CA, USA) according to the manufacturer's guidelines. Products of the sequencing reactions were purified with a NucleoSeq kit (Macherey-Nagel) and sequencing was performed on an AP 310 Genetic Analyzer (Applied Biosystems) in both 
forward and reverse direction. Resulting sequences were assembled and edited with BioEdit (version 7.2.5) using the Contig Alignment Program subroutine [20] and tested for chimeric sequences with the Pintail 1.1 program [21]. Molecular species determination was conducted by comparison of sequences obtained in this study to published sequences using the Megablast algorithm of the BLAST program [22]. Phylogenetic analysis of all small mammal specimens was conducted by sequence alignment in BioEdit (version 7.2.5) and ClustalW [20]. Phylogenetic tree construction was conducted via CIPRES portal, using the FastTreeMP on XSEDE (2.1.9) routine including 1000 bootstraps; the Jukes-Cantor substitution model with Gamma distribution was used [23].

\section{Sequence determination and analysis of the mitochondrial D-loop}

A 647 base pair (bp) fragment of the mitochondrial Dloop was either sequenced as described before [24] or in several cases with an alternative primer pair (forward 5' CTG AAT CCT AGT AGC CAA CC-3' and reverse 5'AGT GTT TTT GGG GTT TGG C-3') using the same conditions. DNA sequencing reactions were conducted with the ABI Big Dye v3.1 Kit (Applied Biosystems) according to the manufacturer's guidelines and analyzed with an ABI 3730 automated sequencer. Raw sequence data were edited using the software CodonCodeAligner 4.04 (CodonCode Corporation, Centerville, MA, USA) and aligned using the ClustalW algorithm implemented in the program MEGA 6.06 [25]. Sequences of $M . m$. domesticus (Norway, Denmark, Germany and France) $[26,27]$ and M. m. musculus (Kazakhstan and Czech Republic) [26] were included as references. Gaps and indels were excluded from the analysis. A Median Joining Network [28] was constructed using the program PopART (http://popart.otago.ac.nz).

\section{Generic PCR for detection of herpesviruses}

DNA was extracted from spleen tissue of 18 house mouse specimens each from an urban area in Cologne (Germany), from a city park in Saarbrücken (Germany) and a rural setting in Radolfzell (Germany) as well as from 36 specimens from Camp Marmal (Afghanistan). DNA samples were obtained with the EURx GeneMATRIX Tissue DNA Purification Kit (Roboklon) according to the protocol "A" described in the manufacturer's guidelines. DNA was visualized on $0.8 \%$ agarose gels to assess DNA quality and quantity. PCR amplification of the cytochrome $b$ gene was conducted for each sample as described above to determine DNA amplificability. Amplification of the DPOL gene was conducted as described before [17]. Briefly, PCR was performed in nested format using a mixture of six degenerated/deoxyinosine substituted primers and delivering an expected
600 bp DNA fragment. The PCR reaction mix of $25 \mu \mathrm{l}$ contained $5.25 \mu \mathrm{l}$ of DNase/RNase free sterile water, $5 \mu \mathrm{l}$ of Colorless GoTaq Flexi buffer (Promega), $2 \mu$ of $25 \mathrm{mM} \mathrm{MgCl}_{2}, 5 \mu \mathrm{l}$ of $5 \mathrm{M}$ betaine (Sigma-Aldrich), $0.5 \mu \mathrm{l}$ of a dNTP mix containing $10 \mu \mathrm{M}$ of each dNTP (Promega), $1.25 \mu \mathrm{l}$ of dimethyl sulfoxide (DMSO), $2 \mu \mathrm{l}$ of a primer mix containing $100 \mathrm{nM}$ of each primer DFA[n/i] f (GAY TTY GC(N/i) AGY YT(N/i) TAY CC, ILK[n/i] f (TCC TGG ACA AGC AGC AR(N/i) YSG $\mathrm{C}(\mathrm{N} / \mathrm{i}) \mathrm{M} \mathrm{T}(\mathrm{N} / \mathrm{i})$ AA as well as KG1[n/i] r (GTC TTG CTC ACC AG(N/i) TC(N/i) AC(N/i) CCY TT, 1 U of GoTaq Polymerase (Promega) and $2 \mu$ template DNA. PCR conditions involved an initial denaturation step of $94{ }^{\circ} \mathrm{C}$ for $10 \mathrm{~min}$ followed by 40 cycles of $95{ }^{\circ} \mathrm{C}$ for $20 \mathrm{~s}$, $46{ }^{\circ} \mathrm{C}$ for $30 \mathrm{~s}$ and $72{ }^{\circ} \mathrm{C}$ for $30 \mathrm{~s}$. A final extension step of $72{ }^{\circ} \mathrm{C}$ was conducted for $7 \mathrm{~min}$.

Two microliters of each reaction were applied in a nested PCR reaction using the PCR conditions described above but applying the primers TGV $[\mathrm{n} / \mathrm{i}] \mathrm{f}$ (TGT AAC TCG GTG TAY GG(N/i) TTY AC(N/i) GG(N/i) GT and IYG [n/i] r (CAC AGA GTC CGT RTC (N/i)CC RTA $(\mathrm{D} / \mathrm{i}) \mathrm{AT})$, a reduced extension time of $20 \mathrm{~s}$ and total amount of 30 cycles. Resulting PCR products were subjected to gel electrophoresis in a 3\% agarose gel in $1 \times$ TAE buffer at $100 \mathrm{~V}$ for $45 \mathrm{~min}$. Bands were excised with a scalpel blade and purified using the QiaEx II gel extraction kit (Qiagen) according to the manufacturer's guidelines. Sequencing reactions using the Big Dye v3.1 kit (Applied Biosystems) and DNA sequence analysis were performed as described above. Resulting nucleotide and in silico translated amino acid sequences were amended by sequences from further sites in Germany and the United Kingdom from a previous study as described therein [17] and a reference sequence (accession number AY854167). Alignments of viral nucleotide and amino acid sequences were conducted with BioEdit (version 7.2.5) and ClustalW [20].

\section{Generic RT-PCR for detection of astroviruses}

RNA was extracted from the liver tissue of a total of 120 house mice that originated from Camp Marmal (36 specimens), Saarbrücken, Cologne and Radolfzell (12 specimens each), Gelsenkirchen (urban), Lünen (rural), Stuttgart (animal husbandry) (8 specimens each) as well as from a mouse breeding facility (24 specimens) using the Genematrix DNA/RNA/Protein Universal Purification kit (Roboklon). RNA quality and quantity was assessed as described for DNA extracts above. Amplification of the $R d R p$ gene was conducted with a modified hemi-nested RT-PCR protocol [29]. Briefly, a master mix of $25 \mu \mathrm{l}$ each containing $12.5 \mu \mathrm{l}$ of Superscript ${ }^{\circ}$ III Onestep PCR Buffer, $400 \mathrm{mM} \mathrm{MgSO}$, $10 \mu \mathrm{M}$ each of the forward primers AS1-f (5'-GARTTYGATTGGRCKCGK TAYGA-3') and AS2-f (5'-GARTTYGATTGGRCKAG 
GTAYGA-3') and $20 \mu \mathrm{M}$ of the reverse primer AS3-r (5'-GGYTTKACCCACATNCCRAA-3') as well as $1 \mu \mathrm{l}$ of the Superscript ${ }^{\circ}$ III One-step PCR reagent and $2.5 \mu \mathrm{l}$ of the RNA extracts were applied in each reaction using the PCR program described before [29].

A second PCR was conducted using a master mix of $25 \mu \mathrm{l}$ each containing $2.5 \mu \mathrm{l}$ of Peqlab Pwo Complete buffer (VWR International, Erlangen, Germany), $50 \mu \mathrm{M}$ of each dNTP, $10 \mu \mathrm{M}$ each of the forward primers AS4-f (5'-CGKTAYGATGGKACKATHCC-3) and A5-f (5'AGGTAYGATGGKACKATHCC-3'), $20 \mu \mathrm{M}$ of primer AS3-r and $1 \mathrm{U}$ of Peqlab Pwo polymerase (VWR International) and $2.5 \mu \mathrm{l}$ of the initial PCR mix using the PCR program described before [29]. Resulting PCR products were visualized on a $3 \%$ agarose gel. All samples delivering the expected $422 \mathrm{bp}$ PCR products were subjected to an additional hemi-nested PCR using $50 \mu \mathrm{l}$ reactions containing identical final concentrations of all chemicals and $5 \mu \mathrm{l}$ of RNA extracts to generate additional amounts of PCR product. The complete reactions were subjected to gel electrophoresis on a $3 \%$ agarose gel. All bands of approximately 422 bp were extracted from the gel and purified using the QiaEx II kit (Qiagen) according the manufacturer's guidelines. Sequencing of the resulting bands was conducted with the Big Dye v3.1 kit (Applied Biosystems) and DNA sequence analysis was performed as described above. For the sequencing reactions, final concentrations of $1 \mu \mathrm{M}$ each for a mix of the primers AS4-f and A5- $\mathrm{f}$ as well as $2 \mu \mathrm{M}$ of primer AS3-r were applied. Alignment of viral sequences was conducted as described for herpesviruses. Phylogenetic analysis was performed via CIPRES portal, using the FastTreeMP on XSEDE (2.1.9) routine including 1000 bootstraps with the Jukes-Cantor substitution model and ClustalW, including a discrete Gamma distribution [23].

\section{Results}

\section{Small mammal trapping}

A total of 751 small mammals were trapped in Northern Afghanistan from January 2009 to October 2012. The vast majority of small mammals in this study originated from Camp Marmal (648) while lower numbers were trapped in PRT Fayzabad (27) and PRT Kunduz (61). A total of around 220 mammals were trapped each in 2009 and 2011, while around 100 animals were trapped in each 2010 and 2012. In total, small mammal communities in all three camps consisted of no more than four members of the order Rodentia and two representatives of the order Soricomorpha (Fig. 1). The house mouse (Mus musculus) comprised more than $80 \%$ of trapped animals overall, ranging from 67 to $98 \%$ in all three locations. A total of 629 house mouse specimens were collected which comprised 377 males and 248 females. The sex of the four remaining specimens could not be determined. Thirty-three females $(13.3 \%)$ were pregnant at the time of trapping and carried a total of 205 embryos (an average of 6.2 embryos per female, ranging from 1 to 10 embryos per female). Among the remaining rodents trapped, the gray dwarf hamster (Cricetulus migratorius) was most prominent with an average percentage of $12.8 \%$ of trapped animals which comprised 47 females and 48 males. Six females (12.8\%) were pregnant and carrying an average of 6.5 (ranging from 5 to 9) embryos. The abundance of $C$. migratorius specimens ranged from 0 to $33.3 \%$ of trapped animals in all three sites. Remaining trapped animals could be identified as members of the rodent genera Meriones (2.1\%), Rattus (0.1\%), and the shrew genera Suncus $(0.1 \%)$ and Crocidura (1.1\%). Despite the different numbers of trapped animals in all three sites and a general trend towards a Mus musculus (C. migratorius) dominated small mammal community in Northern Afghan military bases, there were subtle differences between individual bases. In contrast to Camp Marmal, small mammal communities at PRT Fayzabad contained a higher percentage of C. migratorius specimens but no other small mammals. In contrast to this, the mammal community at PRT Kunduz was entirely dominated by $M$. musculus but contained a single trapping of Crocidura cf. suaveolens. Despite a variation in trapping success (Additional file 1: Figure S1) percentages of genera collected at individual annual quarters represent the average community composition. In contrast to all other small mammal species in this study both M. musculus and C. migratorius specimens could be collected throughout the whole period from 2009 to 2012 .

\section{Identification of small mammals by DNA sequencing of the mitochondrial cytochrome $b$ gene}

Specimens initially determined as $M$. musculus showed the highest average identity of the partial cytochrome $b$ gene of 99.1\% (99\% to $100 \%$ ) to reference $M$. musculus musculus sequences from Central Asia (KF697060; AB649551) and a lower average identity of $97.7 \%$ ( $97 \%$ to $98 \%$ ) to various sequences of M. musculus domesticus (Additional file 2: Table S1). Animals identified as gray dwarf hamsters showed an average identity of $96.8 \%$ (91\% to $98 \%$ ) to a reference C. migratorius sequence (AY288508) originating from Northeast Pakistan (Additional file 2: Table S2). All 16 jirds subjected to DNA sequencing displayed an average identity of the mitochondrial cytochrome $b$ gene of 96.9\% (93\% to 99\%) to that of the Libyan Jird (Meriones libycus; AJ851266; see Additional file 2: Table S2). This high sequence similarity was also reflected in a corresponding phylogenetic tree (data not shown). The single Rattus specimen collected in this study showed $93 \%$ sequence identity to R. tanezumi (JQ793907; Additional file 2: Table S2). 

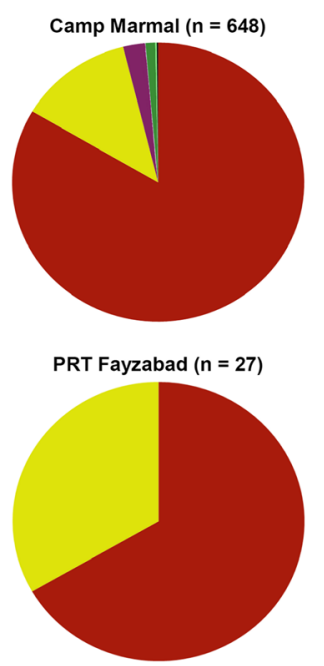

Fig. 1 Percentages of individual species within small mammal communities in Northern Afghan military bases Camp Marmal (Mazar-e-Sharif) as well as PRTs (Provincial Reconstruction Team bases) Kunduz and Fayzabad. Total numbers for each site were $n=648$ for Camp Marmal, $n=27$ for PRT Fayzabad and $n=61$ for PRT Kunduz. Five additional animals were collected at Hazrat-e-Sultan; for 10 animals no trapping site information was available

Among Crocidura specimens, members of Crocidura cf. suaveolens were detected (DQ630062; Additional file 2: Table S3). The Suncus species showed high identity of the cytochrome $b$ gene to Suncus etruscus (FJ716836; Additional file 2: Table S3).

\section{Analysis and comparison of the mitochondrial D-loop from Mus musculus specimens}

The subspecies status of house mice was determined by sequencing of the mitochondrial D-loop region of animals trapped in this study and reference sequences of the Western house mouse (M. m. domesticus) and Eastern house mouse (M. m. musculus) which differ in both genotype and phenotype. A phylogeographic analysis including 214 mitochondrial D-loop sequences revealed mice trapped in this study belong to the $M$. m. musculus clade, and therefore cluster with samples from Kazakhstan and the Czech Republic which serve as a reference for mice from neighboring Germany (e.g. the Leipzig area; Fig. 2). The "musculus"-haplogroup is clearly distinct from M. m. domesticus (from various Western European countries, Africa and South West Asia). Furthermore, Fig. 2 gives evidence for separation of Afghan house mice Dloop sequences from sequences of house mice from the Czech Republic.

\section{Comparison of DNA sequences of Mus musculus rhadinovirus 1 detected in $M$. musculus of different geographic regions}

Using generic DPOL gene PCR for herpesvirus detection in house mouse samples from Camp Marmal and three locations in Germany, a total of 14 out of 114 reactions produced products of approximately 250 bp length each
(Fig. 3). Five out of 60 samples from Camp Marmal, six out of 18 samples from Cologne, two out of 18 samples from Saarbrücken and one out of 18 samples from Radolfzell delivered positive results. All 14 viral sequences showed 97\% similarity to a single MmusRHV1 reference sequence described before (AY854167) [17]. A comparison of the novel sequences from Camp Marmal/ Afghanistan (MeS), Cologne (COL), Saarbrücken (SBR) and Radolfzell (RAZ), and those for the Leverkusen (LEK), Roklum (ROK) and Liverpool (LIV) sites generated in an earlier study [17] indicated that all sequences from any given site were identical to each other, with exception of one sequence from the Leverkusen site (number LEK_1; Fig. 3). Viral sequences for each trapping location showed a unique DPOL DNA sequence with the exception of identical sequences from the sites Cologne (COL_1 - COL_6)/Radolfzell (RAZ_1) and Liverpool (LIV_1 - LIV_4)/Leverkusen (LEK_2 - LEK_9). The other European MmusRHV1 DNA sequences showed a difference in a single nucleotide (Roklum, ROK, position 148; Saarbrücken, SBR, position 158). Similarly, sequences obtained from Camp Marmal/ Afghanistan differed from all European sequences in two positions (10 and 157). Partial amino acid sequences of the deduced DPOL protein show that most of the nucleotide differences are silent and do not translate into amino acid substitutions (Additional file 3: Figure S2). DPOL amino acid sequences from MmusRHV1 detected in house mice from Camp Marmal and all other sites were almost identical, however, all sequences from Saarbrücken showed a substitution of isoleucine for valine in position 53 and all sequences from Roklum including the reference sequence displayed a substitution 


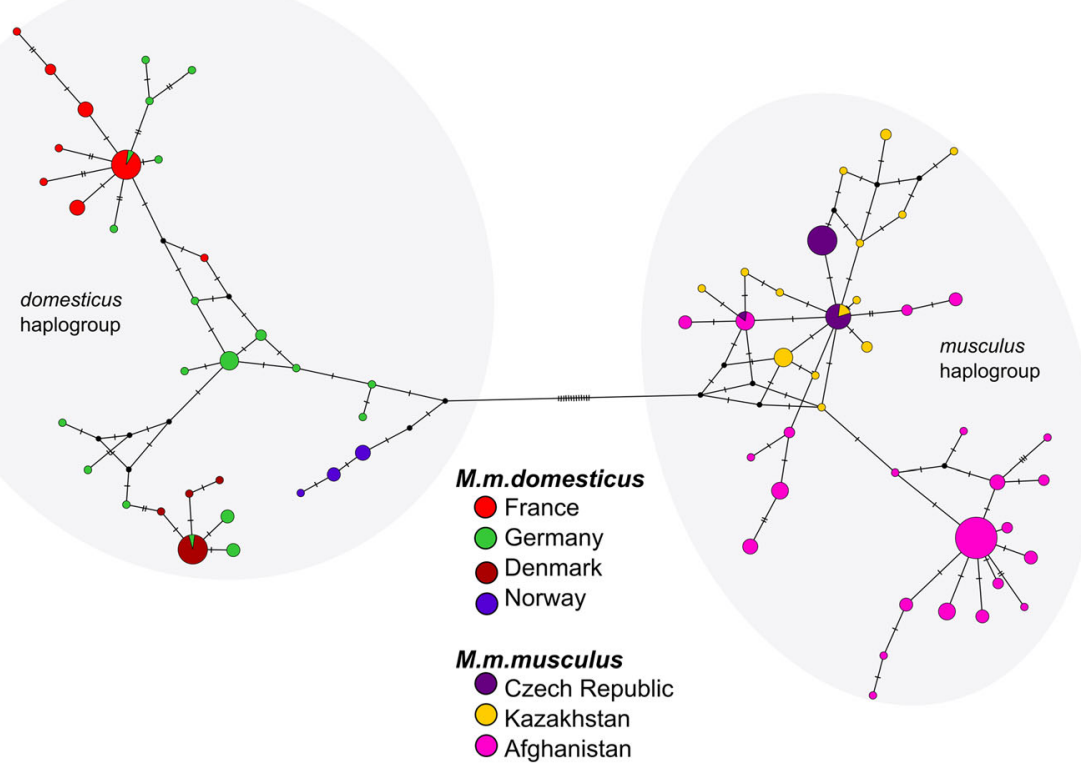

Fig. 2 Median Joining Network of 214 mitochondrial D-loop sequences of house mice. The relationship between individuals of seven populations, representing the two most prominent subspecies of house mice M. m. musculus and M. m. domesticus are shown. Mice collected in Afghanistan could be clearly attributed to M. m. musculus. The number of mutation steps is given as hatch marks

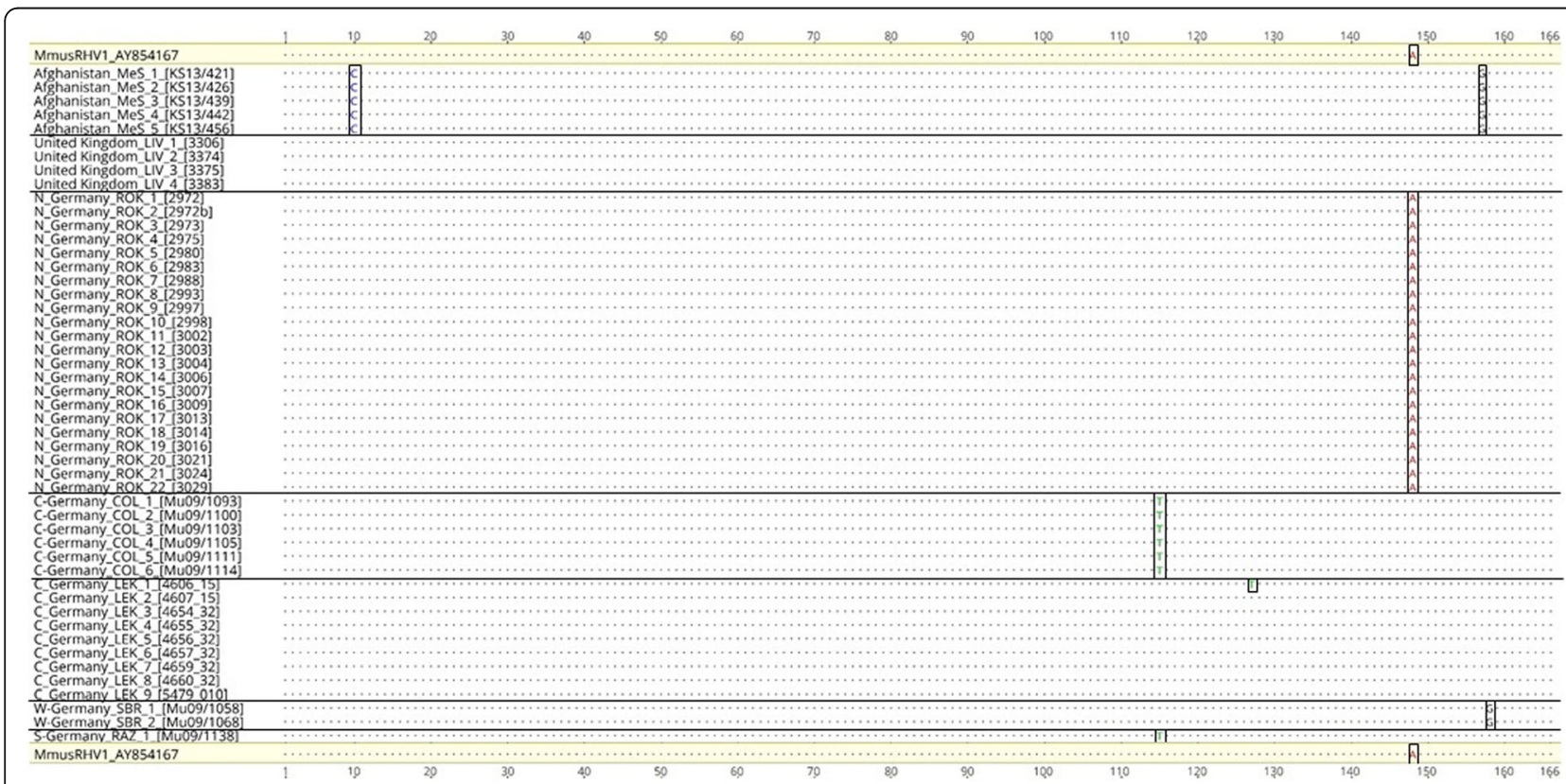

Fig. 3 Comparison of partial DNA sequences of the DPOL gene of MmusRHV1 from Mus musculus specimens collected in Afghanistan, Germany and the United Kingdom to a reference sequence from Germany. All sequences from Afghanistan originated from Camp Marmal (Mazar-e-Sharif $(\mathrm{MeS})$ ), whereas all sequences from the United Kingdom originated from Liverpool (LIV). Sequences from Germany resulted from specimens trapped in Northern (N) Germany (Roklum (ROK)), Central (C) Germany (Cologne (COL) and Leverkusen (LEK)), Southwest (W) Germany (Saarbrücken (SBR)) as well as South (S) Germany (Radolfzell (RAZ)). Nucleotide exchanges in the DPOL sequence of MmusRHV1 strains are marked. Included sequences were generated in this study (Afghanistan: 5, Cologne: 6, Saarbrücken: 2, Radolfzell: $1 ; n=14$ ) or have been determined in a reference study (Leverkusen: 9, Roklum: 22, Liverpool: 4; $n=35$; [17]) 
of glutamic to aspartic acid in position 49 compared to all other sequences.

\section{Detection of astrovirus RNA sequences in M. musculus from Afghanistan and Germany}

The generic astrovirus RT-PCR showed for 13 out of 120 samples products of about $400 \mathrm{bp}$. Seven out of 36 samples from Camp Marmal, four out of eight samples from Gelsenkirchen and Lünen, one out of eight samples from Stuttgart and one out of 12 samples from Radolfzell delivered positive results. No positive samples were obtained from the mouse breeding facility. Two distinct types of astroviruses were observed: a sample from Radolfzell as well as one out of seven samples from Camp Marmal displayed 84\% identity to rat astroviruses (e.g. rat astrovirus RS297, accession number HM450385), whereas all other astrovirus sequences detected in this study showed an average of 92\% (range: 89\% to 93\%) identity to house mouse astroviruses (e.g. astrovirus TF20LM, accession number JQ408742). A phylogenetic analysis of the 13 novel sequences and 33 astrovirus reference sequences highlights this apparent difference (Fig. 4).

\section{Discussion}

\section{Composition of the small mammal community of FSB} camp Marmal and PRTs Fayzabad and Kunduz

Military bases of the $21^{\text {st }}$ century offer a multitude of ecological niches for commensal rodents within artificial human environments. This is especially true for temporary or makeshift bases set up in countries with infrastructure deteriorated by war such as Afghanistan, which offer a unique combination of high accessibility and large amounts of resources for commensalic small mammals capable of exploiting them. As a result, rodent communities determined in this study were strongly dominated by $M$. musculus. The overall small mammal diversity in all trapping sites was very low with a total of six small mammal species, four of which belonged to the order Rodentia. The highest diversity of small mammals was observed for the Camp Marmal site. In contrast, only two species each were encountered at the PRT Kunduz and the PRT Fayzabad site, albeit the total amount of animals trapped at both PRTs was significantly lower for PRT Kunduz $(n=61)$ and PRT Fayzabad $(n=27)$ than for Camp Marmal $(n=648)$. Among the small mammal fraction were sporadic trappings of insectivores, such as Crocidura cf. suaveolens and Suncus etruscus which could have been attracted by invertebrates feeding on such bait. Only a single specimen of the genus Rattus was collected during the study time of almost three years. This specimen had a high identity of the cytochrome $b$ gene to $R$. tanezumi, a species commonly encountered in Central Asia. Gray dwarf hamsters (Cricetulus migratorius) and jirds (Meriones libycus) proved to be the second and third most abundant mammals trapped. Gray dwarf hamsters accounted for $12.8 \%$ of trappings. This omnivorous (granivorous/insectivorous) rodent is widespread through Central Asia and can inhabit a large variety of grassland habitat, especially at high altitudes. In contrast to Mus musculus this species prevails in very dry habitats and was reported to have a significantly lower litter size and birth rate [30]. However, the results of our study show that both the possible litter sizes and the percentage of pregnant females of both species were similar. Similar to C. migratorius, Meriones libycus trapped in this study are relatively widespread burrowing rodents. These animals are strongly adapted to arid environments and can entirely cover their water supply through their food sources [31].

The small mammal species trapped in this study however only represents a snapshot of the true small mammal diversity of Afghanistan. While the predominant species detected in this study, Mus musculus, Meriones libycus and C. migratorius have been observed in previous studies from Afghanistan [10,11] and a study from Northeastern Iran [32], the total small mammal diversity of this region also comprises members of the genera Calomyscus, Alticola, Blanfordimys, Ellobius, Microtus, Allactaga, Jaculus, Dryomys, Salpingotus, Gerbillus, Apodemus, Nesokia, Rattus, Tatera and Sorex.

The limited small mammal diversity detected at the three sampling sites Mazar-e-Sharif, Fayzabad and Kunduz within the dataset however is not unusual for urban settings. Previous studies from Vancouver, Canada [33], and Buenos Aires, Argentina [34], have shown that urban small mammal communities are dominated by Rattus norvegicus, Rattus rattus or Mus musculus. A pivotal factor determining which of the three species dominates an urban environment is the structure and microenvironment provided by the specific location. These species excel in microenvironments that contain man-made structures as well as rural habitats, e.g. shanty towns or parklands, but struggle to compete with other rodents in less urbanized regions. The three trapping sites investigated in this study were semi-temporary urban environments with an unusually high transition rate of human personnel and goods. Due to the military use of the trapping sites, density of human personnel per square meter was very high and accommodation was available in the shape of container architecture. For logistical and strategic reasons, all three trapping sites were located adjacent to local air strips or at the outskirts of the actual cities of Mazar-e-Sharif, Fayzabad and Kunduz and were embedded in a predominantly rural surrounding. This setting therefore may select small mammal communities for commensals such as $M$. musculus due to both easy accesses in and out of the base but also offers easy access to food resources. In 


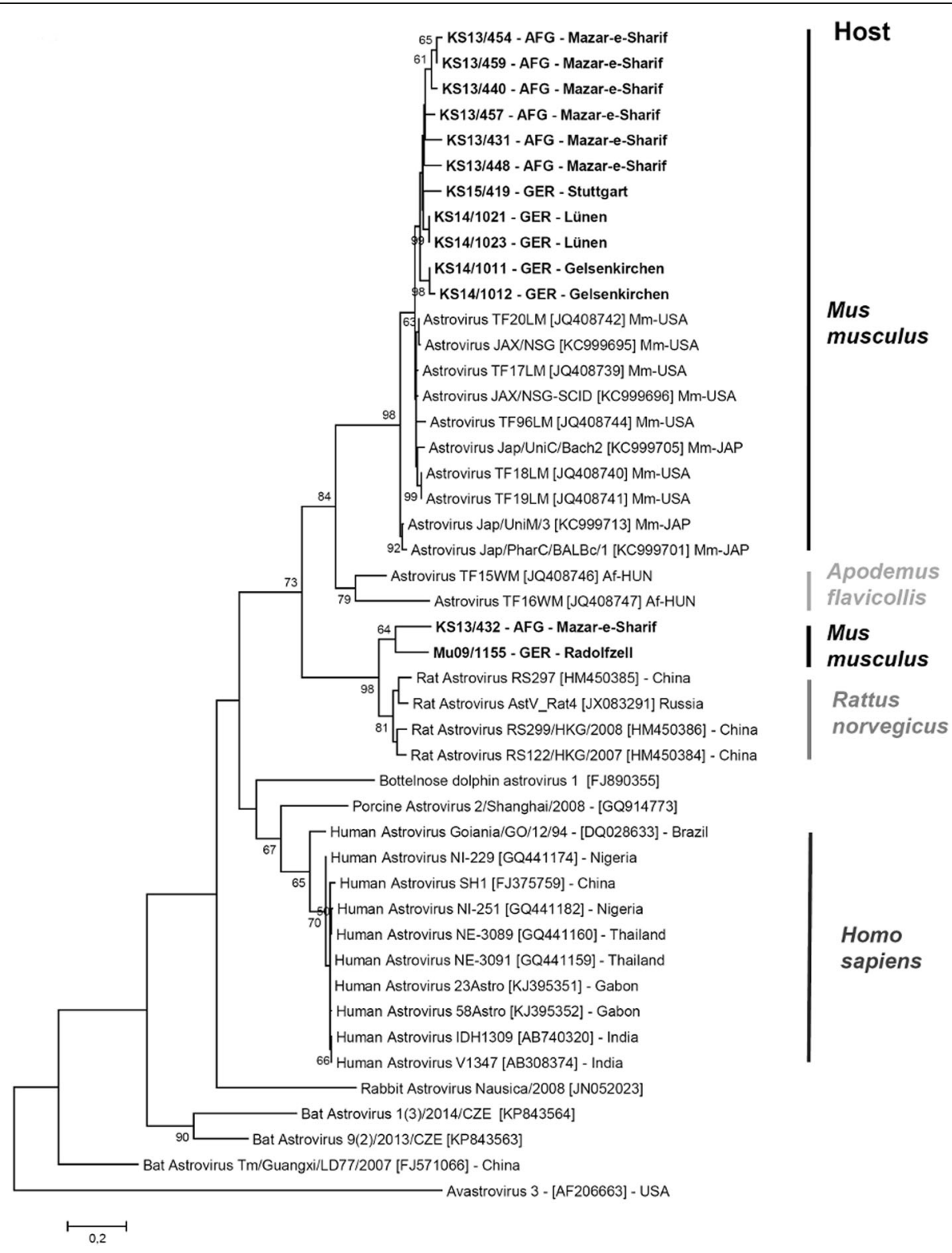

Fig. 4 Molecular phylogenetic analysis of astrovirus sequences from house mice collected in Afghanistan and Germany as well as reference sequences from the United States and Japan by Maximum Likelihood method. The evolutionary history was inferred by using the Maximum Likelihood method based on the Jukes-Cantor Model. Bootstrapping with 1000 replications was performed and support values below 50\% were omitted in the figure for clarity. A discrete Gamma distribution was used to model evolutionary rate differences among sites ( 5 categories $(+G)$. The analysis involved 46 nucleotide sequences. All positions containing gaps and missing data were eliminated. There were a total of 231 positions in the final dataset. Evolutionary analyses were conducted via CIPRES portal using the FastTreeMP on XSEDE (2.1.9) routine [23]

contrast to the patchy rodent population composition and density in an urban environment observed in Vancouver [33], the communities in Camp Marmal, PRT Kunduz and PRT Fayzabad showed a relatively similar composition concerning the dominance of house mice and occurrence of gray dwarf hamsters. This could be due to the modular and standardized design of makeshift military bases developed for missions such as ISAF. Similar to rodent communities observed in Buenos Aires [34], Camp Marmal and the PRTs Kunduz and Fayzabad also contained hemerophobic rodent species, e.g. C. migratorius and Meriones libycus. A previous study conducted in habitats similar to the Afghan trapping sites in Uzbekistan showed presence of both species and indicated preferences for similar microenvironments and food sources [30]. While C. migratorius is a granivorous and insectivorous rodent 
that prefers rocky or gravely surfaces, Meriones libycus was primarily trapped on sandy ground and prefers green vegetation and seeds [30, 31].

The results of this study greatly vary from an earlier report on rodent sightings in Camp Marmal in the period from 2004 to 2006. Within this time, a major ZCL outbreak occurred in this area that involved more than 4200 cases within a period of 36 months and was attributed to a high abundance of great gerbils (Rhombomys opimus) and transmission by Phlebotomus papatasi sandflies [3]. Interestingly, no specimens of $R$. opimus could be detected among the rodents collected in the present study. The presence of $R$. opimus in the vicinity of humans in Northern Afghanistan is associated with infrastructure degradation due to the Afghan Civil War and agricultural changes e.g. the construction of irrigation canals for intensified crop in the 1980's. In case of Camp Marmal, the massive increase of the local R. opimus population was attributed to banks of loose soil erected during construction works in the vicinity of the base. By 2006, the soil banks were removed, graveled or replaced by a concrete wall surrounding parts of the base [5]. These modifications in combination with pest control measures, the reconstruction of infrastructure as well as the introduction of food sources more suitable to commensalic rodents (e.g. Mus musculus) therefore may have changed the habitat to the disadvantage of $R$. opimus while simultaneously preventing from Leishmania spp. infection by interrupting the local main transmission mode [5].

\section{Origins of house mice ( $M$. musculus) trapped in military bases of northern Afghanistan}

An essential question resulting from our data is the origin of the small mammals trapped in this study. As Camp Marmal received large quantities of goods via air transport from Leipzig, Germany, to Kabul and successive land transport during the trapping period [1] most supplies for the base hence originated from Germany or nations sharing the base (e.g. Denmark and Norway). It is not unlikely that within such a large logistic operation, an ubiquitous and invasive species such as $M$. musculus could have been accidentally introduced into the military base through supply crates or containers from Europe. Similarly, indigenous populations of $M$. musculus could have been recruited into the Northern Afghan bases by providing local animals with an environment and food sources suitable for them.

Even though the phylogeography of the house mouse is not fully resolved yet, it is clear that the house mouse is split up into at least three distinct subspecies, $M$. musculus domesticus, $M$. musculus musculus and M. musculus castaneus [35] which are already well known. Furthermore, the clade $M$. musculus bactrianus has been recently confirmed [36, 37]. Among these, two predominant subspecies, M. musculus domesticus (the Western house mouse) and M. musculus musculus (the Eastern house mouse) are spread globally due to human colonization. While M. m. domesticus is predominant in Western Europe and Northern Africa, Australia and the Americas, M. $m$. musculus can be found in the continental climate of Eastern Europe and Asia [38-41]. A hybridization zone of both subspecies has been observed in Eastern Germany and Austria extending through the Adriatic coast [38-41]. However, hybrids of Eastern and Western house mice in the European hybridization zone are considered significantly less competitive than members of each subspecies through a series of genetic mechanisms [42-45].

In this study, we investigated the origin of house mice trapped at three sites in Afghanistan with several techniques: First, amplification and sequencing of the cytochrome $b$ gene enabled a quick detection of subspecies of M. musculus. All analyzed specimens of house mice trapped at the three Afghan sites showed a high similarity of the cytochrome $b$ gene to $M$. m. musculus but a lower similarity to $M$. $m$. domesticus. These findings were supported by the analysis of the mitochondrial Dloop region. All 85 sequences of animals trapped in this study used for the analysis of the mitochondrial D-loop region did unequivocally cluster with sequences obtained from M. m. musculus specimens originating from Central Asia in an earlier study [41], which also confirms the finding of Prager et al. (1998) [46].

Further, this analysis also shows that transports from airports close to the European $M . m$. musculus populations (i.e. the airports in Eastern Germany, Denmark and Norway) were less likely the source of the mice sampled in Afghanistan (Fig. 2). In case of Eastern German Airports, D-loop sequences of $M$. m. musculus from the Czech Republic were used as reference due to their geographic proximity. The results presented above are supported furthermore by a recent study that compared wild populations of house mice from eight Eurasian locations (including specimens from Camp Marmal) by whole genome sequencing [47]. These results clearly show substantial differences between Eastern European and Central Asian specimens of M. musculus musculus on the level of the whole genome. Furthermore, that study included female and male individuals and there is no evidence of male import from Western Europe to Afghanistan [47].

A limitation of both methods that are based on mitochondrial DNA that is solely inherited from the maternal lineages is their incapability of detecting hybrid offspring of male $M . m$. musculus specimens that could have been introduced from Eastern German airports into Afghanistan. In contrast to conventionally used methods to overcome this limitation (e.g. microsatellite analysis), this study investigated viral DNA and RNA sequences of the polymerase genes of MmusRHV1 and murine astroviruses as alternative markers to test their suitability for this very purpose. 
MmusRHV1 has so far exclusively been detected in Mus musculus and the DPOL gene is highly conserved in contrast to other genes within the viral genome (e.g. the gene coding for glycoprotein B) [17]. The results of this study confirm the conserved nature of the DPOL gene of MmusRHV1, but show distinct local patterns of nucleotide variations. Out of the sequence dataset obtained from Afghanistan and six different locations in Europe, unique nucleotide exchanges were detected at two sites in Germany (Saarbrücken and Roklum), whereas identical sequences were found at locations Cologne/Radolfzell and Liverpool/Leverkusen. Interestingly, different sequences for the $D P O L$ gene were observed in specimens from Cologne and Leverkusen, two neighboring cities on opposing banks of the river Rhine. Afghan MmusRHV1 sequences displayed two unique and silent nucleotide exchanges that did not occur in European samples. Nucleotide substitutions in the DNA sequence of MmusRHV1 proved to affect the amino acid sequence of the actual DPOL protein in only two positions within the whole dataset analyzed in this study (positions 49 and 53). In the first case aspartic acid was substituted for glutamic acid, whereas in the second case isoleucine was substituted for valine and thus involved amino acids with similar chemical properties and functional groups. This combination of conserved DNA sequence but location-specific nucleotide variations makes the partial $D P O L$ gene of MmusRHV1 a promising candidate for a novel phylogeographic marker for the analysis of geographic origins of Mus musculus specimens. Yet, a limiting factor of this method could be the percentage of infected animals. In this study, an average of $12.3 \%(14 / 114)$ of Afghan house mice was infected with MmusRHV1 which was slightly lower than in a previous study [17]. As it cannot a priori be assumed that a high enough percentage of a house mouse population at each trapping site is infected with MmusRHV1, the current procedure requires trapping and processing of large numbers of house mice to provide a statistically valid data set for each trapping site. Further problems could be the relatively low sensitivity of the nested pan-PCR used in this study or the fact that herpesviruses are more complicated to be detected during latency.

To back up the results obtained for MmusRHV1, a dsDNA virus, another virus that shows high prevalence in house mouse populations was investigated in this study. For that purpose, astroviruses were selected as an example of a ssRNA virus frequently detected in rodents and more specifically in house mice [48-50]. As they are RNA viruses, murine astroviruses are in general prone to a high sequence variability driven by the lacking proof-reading function of the $R d R p$ as well as specific features of the astrovirus genome. In addition, these viruses are also capable of genomic recombination which has already been described for human astroviruses [50, 51]. In the case of this study, two different genotypes of astroviruses were detected each in house mice from Afghanistan and Germany. While most of the novel astrovirus sequences have shown high similarities to other murine astrovirus sequences, a single sequence each from Afghanistan and Germany did group with rat astroviruses. Within the murine astroviruses, no apparent grouping into location-specific groups could be detected. The apparent high sequence variability of the region analyzed in this study in combination with a relatively small database of murine astrovirus genomes available at this moment of time therefore currently make astroviruses a less suitable candidate for virus-based phylogeographical analysis than gammaherpesviruses, i.e. MmusRHV1.

Finally, the combined results of three of the four methods tested indicate that the establishment of an invasive house mouse population originating from Northern, Central or Western Europe after a hypothetical transportation is unlikely. These findings are supported by a previous study conducted on the Kerguelen Archipelago and other Southern Ocean Islands [14]. D-loop analysis indicated that the house mouse population that conducts the primary invasion of the islands cannot be superseded by a secondary invasion of the same species. The mechanism for this resilience against either takeover or interbreeding of primary colonizers by secondary colonizers is presumed to be due to quick adaptations to biotic and abiotic factors of the new habitat. Primary driving forces for these adaptations may be climate, food sources and microhabitat structure [14, 15, 27]. In case of the Kerguelen Archipelago, Western house mice from Europe performed the primary invasion and quickly adapted to a colder climate, a diet mainly based on insects as well as a less structured habitat due to the high number of offspring and low generation time. Therefore, secondary colonizers invading the islands faced an already adapted population of competitors. In case of the Afghan military camps, house mice must be adapted to a significantly harsher and drier continental climate at elevated altitude and to a desert habitat with significantly less cover and vegetation in comparison to habitats in Central Europe.

\section{Outlook - Mus musculus as dominant commensal of ISAF garrisons in northern Afghanistan}

The results of previous research [33, 34] as well as this study imply that rodent communities dominated by house mice may form spontaneously in sites like Camp Marmal due to the habitat structure and food sources introduced by the construction of the military bases. While these results urgently require further investigation in military bases of similar design, they may indicate an effect of this specific rodent species on life in Northern Afghanistan military bases. From 2004 to 2006, high numbers of Rhombomys opimus were detected in the vicinity of Camp Marmal due to earth works, yet for the period from 2009 to 2012 after having implemented 
continuous $R$. opimus control including environmental changes, none of the trapped mammals belonged to this species. While another possible reservoir host for Leishmania spp., Meriones libycus [52], was trapped within the Camp Marmal site, it only represented $2.1 \%$ of total trapped animals. This may indicate that $R$. opimus-dominated communities inside Camp Marmal site from 2004 to 2006 were superseded by house mouse-dominated communities by 2010 . In contrast to this species, house mice are known to be carriers of other pathogens such as lymphocytic choriomeningitis virus, Leptospira spp., Rickettsia spp. and Salmonella spp. [53]. The presence of a house mouse population in the military camps in this study therefore may have provided a surrounding with significantly lower number of reservoir hosts of zoonotic pathogens such as Leishmania spp. for both soldiers and civilian personnel. Hence, house mice in Camp Marmal and the PRTs Kunduz and Fayzabad have successfully colonized a habitat previously occupied by reservoir hosts of such pathogens. However, further studies could provide an insight if this is a common process occurring throughout Afghanistan (or in fact other military bases in development on other continents) and more importantly, if this process is reversed after the end of the military operations, e.g. by investigating current rodent communities in now abandoned Northern Afghan military bases and determining the prevalence of zoonotic pathogens within them.

\section{Conclusions}

The results of this study highlight that changes in the architecture and design of the makeshift military bases investigated affected the resident rodent communities as the population of $R$. opimus encountered before 2009 disappeared from the bases and a rodent population dominated by Eastern house mice could be found after this point in time. Albeit a relatively low probability of undetected hybridization of introduced and local house mice, both maternal mitochondrial DNA markers and viral marker genes of a DNA virus infecting these Afghan rodents indicate that an introduction of $M$. musculus musculus from Europe seems unlikely.

\section{Additional files}

Additional file 1: Percentages of individual species within small mammal communities in Northern Afghan military bases as well as Provincial Reconstruction Team bases with regard to the time of trapping. (DOCX $130 \mathrm{~kb}$ )

Additional file 2: Results of DNA sequencing of the cytochrome $b$ gene of animals phenotypically identified as house mice (Mus musculus), gray dwarf hamsters (Cricetulus migratorius), jirds (Meriones spp.), rat (Rattus spp.) and as members of the shrew genera Suncus and Crocidura. (DOC 206 kb)

Additional file 3: Comparison of partial amino acid sequences of the deduced DPOL protein of MmusRHV1 from Mus musculus specimens trapped in Afghanistan, Germany and the United Kingdom to a reference sequence from Germany. (DOCX $472 \mathrm{~kb}$ )

\section{Abbreviations}

bp: base pair; COL: Cologne; DMSO: Dimethyl sulfoxide; DPOL: DNA polymerase; ds: double stranded; FOB: Forward Operating Base; FSB: Forward Support Base; ISAF: International Security Assistence Force; LEK: Leverkusen; LIV: Liverpool; MeS: Mazar-e-Sharif, Camp Marmal/Afghanistan; MmusRHV1: Mus musculus Rhadinovirus 1; PRT: Provincial Reconstruction Team; RAZ: Radolfzell; RdRp: RNA-dependent RNA polymerase; ROK: Roklum; SBR: Saarbrücken; ss: single stranded; ZCL: Zoonotic Cutaneous Leismaniasis

\section{Acknowledgements}

The authors thank the ISAF staff of Camp Marmal, PRT Kunduz and PRT Fayzabad and in particular all veterinarian teams and numerous preventive medicine technicians. We acknowledge LtCol Alfred Binder for his contributions to veterinary science which form the bases of our study, and Dr. Ulrich Schotte for critical reading the manuscript and helpful comments. The authors thank Anke Mandelkow, Marie Luisa Schmidt, Maria Justiniano Suarez and Dörte Kaufmann for their excellent technical assistance, and Ulrike M. Rosenfeld, Sabrina Schmidt, Hanan Sheikh Ali, Elisa Heuser, Julia Schneider, Franziska Thomas, Maysaa Dafalla and Stefan Fischer for their help during dissections and laboratory work, Stephan Drewes for assistance in dissections and data analysis as well as Carina Spahr and Richard Kruczewski for kindly providing house mouse specimens.

\section{Funding}

These investigations were funded by contract-research-projects for the Bundeswehr Medical Service M/SABX/005 and E/U2 AD/CF512/DF557.

\section{Availability of data and materials}

All DNA sequences obtained from this study were submitted to GenBank (https://www.ncbi.nlm.nih.gov/genbank). Nonredundant cytochrome b DNA sequences of rodents were submitted under the accession numbers MF535299 to MF535312, whereas D-loop sequences obtained from Afghan house mice were deposited with the accession numbers KP411297 to KP411381. MmusRHV1 sequences obtained from Germany, Afghanistan and the United Kingdom were deposited in GenBank with the accession numbers KP411248 to KP411296 and astrovirus sequences obtained from Germany and Afghanistan with the accession numbers KU189261 to KU189273.

\section{Authors' contributions}

Conceived and designed the study: CG MS JPT DT SS RGU. Performed research: CG MS ML JL KB AB RR. Analyzed data: CG MS RH ML. Contributed new methods or models: KF BE PK. Wrote the paper: CG RH MF SS BE ML RR KF DT RGU. All authors read and approved the final manuscript.

\section{Ethics approval and consent to participate}

As the trappings of small mammals were conducted as part of regular pest control measures in accordance with the NATO Standardized Agreement 2048 "Deployment Pest and Vector Surveillance and Control ", no approval by an ethics committee was required. No field permit was required as trappings in Afghanistan took place within the boundaries of ISAF property and were conducted by ISAF staff. For astrovirus investigations, additional $M$. musculus domesticus and M. m. musculus specimens were collected within the network "Rodent-borne pathogens" in 2015 in Westphalia, Germany by a pest controller and from a scientific mouse breeding facility described before [18]. These animals in North Rhine-Westphalia were collected by a cooperation partner as part of its pest control measures. Therefore, specific animal ethics permits were not required. All trappings in Afghanistan, Germany and the United Kingdom were performed in accordance with the Animal Welfare Act of the Federal Republic of Germany (TierSchG; BGBI. S. 1206 (2006)) and the Animal Welfare Act 2006 of the United Kingdom. Snap traps and trapping procedures were in compliance with DIN10523. No endangered species were trapped.

Consent for publication

Not applicable.

Competing interests

The authors declare that they have no competing interests.

\section{Publisher's Note}

Springer Nature remains neutral with regard to jurisdictional claims in published maps and institutional affiliations. 


\section{Author details}

Friedrich-Loeffler-Institut, Federal Research Institute for Animal Health, Institute of Novel and Emerging Infectious Diseases, Greifswald-Insel Riems, Greifswald, Germany. ${ }^{2}$ Max Planck Institute of Evolutionary Biology, Plön, Germany. ${ }^{3}$ Stiftung Zoologisches Forschungsmuseum Alexander Koenig, ZFMK, Bonn, Germany. ${ }^{4}$ Friedrich-Loeffler-Institut, Federal Research Institute for Animal Health, Institute of Diagnostic Virology, Greifswald-Insel Riems, Greifswald, Germany. ${ }^{5}$ Robert Koch-Institut, Division 12 "Measles, Mumps, Rubella, and Viruses Affecting Immunocompromised Patients", Berlin, Germany. ${ }^{6}$ Landratsamt Weilheim-Schongau Veterinäramt, Weilheim i. OB, Germany. 'Bundeswehr Medical Academy, Military Medical Research and Development, Division E, Munich, Germany. ${ }^{8}$ Friedrich-Loeffler-Institut, Federal Research Institute for Animal Health, Department of Experimental Animal Facilities and Biorisk Management, Greifswald-Insel Riems, Greifswald, Germany. ${ }^{9}$ Zentrales Institut des Sanitätsdienstes der Bundeswehr Koblenz, Abteilung I Medizin, Koblenz, Germany. ${ }^{10}$ German Center for Infection Research (DZIF), Partner Site Hamburg-Luebeck-Borstel-Insel Riems, Greifswald-Insel Riems, Greifswald, Germany. ${ }^{11}$ Present Address: RWTH Aachen, Institute for Biotechnology, Aachen, Germany. ${ }^{12}$ Present Address: Seramun Diagnostica GmbH, Heidesee, Germany.

Received: 5 December 2016 Accepted: 26 October 2017 Published online: 15 November 2017

\section{References}

1. Chiari B. From Venus to Mars? Provincial reconstruction teams and the European military experience in Afghanistan, 2001-2014. Freiburg i. Breisgau: Rombach Verlag AG; 2014.

2. Wallace MR, Hale BR, Utz GC, Olson PE, Earhart KC, et al. Endemic infectious diseases of Afghanistan. Clin Infect Dis. 2002;34:171-207.

3. Faulde M, Schrader J, Heyl G, Amirih M, Hoerauf A. Zoonotic cutaneous leishmaniasis outbreak in Mazar-e Sharif, northern Afghanistan: an epidemiological evaluation. Internat. J Med Microbiol. 2008;298:543-50.

4. Faulde M, Heyl G, Amirih ML. Zoonotic cutaneous leishmaniasis, Afghanistan. Emerg Inf Dis. 2006;12:1623-4.

5. Faulde M, Schrader J, Heyl G, Hoerauf A. High efficacy of integrated preventive measures against zoonotic cutaneous leishmaniasis in northern Afghanistan, as revealed by quantified infection rates. Acta Trop. 2009;110:28-34.

6. Lee HW, Baek $\amalg$, Johnson KM. Isolation of the etiologic agent of Korean hemorrhagic fever. J Infect Dis. 1978;137:298-308.

7. Bugert JJ, Welzel TM, Zeier M, Darai G. Hantavirus infection-haemorrhagic fever in the Balkans-potential nephrological hazards in the Kosovo war. Nephrol Dial Transplant. 1999;14:1843-4.

8. Press and Media Section, North Atlantic Treaty Organization (NATO). Afghanistan report 2009. NATO, public diplomacy division, press and media section, media operation center (MOC)2009. Available: www.nato.int.

9. Press and Media Section, North Atlantic Treaty Organization (NATO). International Security Assistance Force (ISAF). Key facts and figures. NATO, Public Diplomacy Division, Press and Media Section, Media Operation Center (MOC). 2009. Available: www.nato.int.

10. Hassinger JD. Street expedition to Afghanistan. A survey of the mammals of Afghanistan, resulting from the 1965 street expedition (excluding bats) [by] Jerry D. Hassinger. [Chicago]: Field Museum of Nat Hist; 1973.

11. Mohammadian H. An introduction to mammals of Afghanistan. Teheran, Iran: Shabpareh Publishing Institute; 2011.

12. Tattershall FN, Smith RH, Nowell F. Experimental colonization of contrasting habitats by house mice. Z Säugetierkunde. 1997;62:350-8.

13. Pelz $\mathrm{H}-J$, Rost $\mathrm{S}$, Müller E, Esther A, Ulrich RG, et al. Distribution and frequency of VKORC1 sequence variants conferring resistance to anticoagulants in Mus musculus. Pest Manag Sci. 2012;68:254-9.

14. Hardouin EA, Chapuis J-L, Stevens MI, van Vuuren J, Quillfeldt $P$, et al. House mouse colonization patterns on the sub-Antarctic Kerguelen archipelago suggest singular primary invasions and resilience against re-invasion. BMC Evol Biol. 2010;10:325.

15. Babiker H, Tautz D. Molecular and phenotypic distinction of the very recently evolved insular subspecies Mus musculus helgolandicus Zimmermann, 1953. BMC Evol Biol. 2015;15:160. doi:10.1186/s12862-015-0439-5.

16. Schlegel M, Baumann K, Breithaupt A, Binder A, Schotte $U$, et al. What about the role of rodents as vectors for zoonotic pathogens in mission areas of the Bundeswehr? Wehrmed Monatsschrift 2012;56:203-207. [in German].
17. Ehlers B, Kuchler J, Yasmum N, Dural G, Voigt S, et al. Identification of novel rodent herpesviruses, including the first gammaherpesvirus of Mus musculus. J Virol. 2007:81:8091-100.

18. Hasenkamp N, Solomon T, Tautz D. Selective sweeps versus introgression population genetic dynamics of the murine leukemia virus receptor Xpr1 in wild populations of the house mouse (Mus musculus). BMC Evol Biol. 2015; 15:248. doi:10.1186/s12862-015-0528-5.

19. Schlegel M, Ali HS, Stieger N, Groschup MH, Wolf R, et al. Molecular identification of small mammal species using novel cytochrome b genederived degenerated primers. Biochem Genet. 2012;50:440-7.

20. Hall T. BioEdit: a user-friendly biological sequence alignment editor and analysis program for windows 95/98/NT. Nucleic Acid Symp. 1999;41:95-8.

21. Ashelford KE, Chuzhanova NA, Fry JC, Jones AJ, Weightman AJ. At least 1 in 20165 rRNA sequence records currently held in public repositories is estimated to contain substantial anomalies. Appl Environ Microbiol. 2005;71:7724-36.

22. Altschul SF, Gish W, Miller W, Myers EW, Lipman DJ. Basic local alignment search tool. J Mol Biol. 1990;215:403-10.

23. Miller MA, Pfeiffer W, Schwartz T. Creating the CIPRES Science Gateway for inference of large phylogenetic trees. In: Proceedings of the Gateway Computing Environments Workshop (GCE), 14 Nov. 2010, New Orleans, LA, pp 1-8.

24. Prager EM, Sage RD, Gyllensten U, Thomas WK, Hübner $R$, et al. Mitochondrial DNA sequence diversity and the colonization of Scandinavia by house mice from East Holstein. Biol J Linnean Soc. 1993:50:85-122.

25. Tamura K, Stecher G, Peterson D, Filipski A, Kumar S. MEGA6:Molecular Evolutionary Genetics Analysis version 6.0. Mol Biol Evol. 2013;30:2725-9.

26. Ihle S, Ravaoarimanana I, Thomas M, Tautz D. An analysis of signatures of selective sweeps in natural populations of the house mouse. Mol Biol Evol. 2006;23:790-7.

27. Bonhomme F, Orth A, Cucchi T, Rajabi-Maham H, Catalan J, Boursot P, et al. Genetic differentiation of the house mouse around the Mediterranean basin: matrilineal footprints of early and late colonization. Proc R Soc B. 2011;278:1034-43.

28. Bandelt $H$, Forster $P$, Röhl A. Median-joining networks for inferring intraspecific phylogenies. Mol Biol Evol. 1999;16:37-48.

29. Chu DKW, Poon LLM, Guan Y, Peiris JSM. Novel astroviruses in insectivorous bats. J Virol. 2008:82:9107-14.

30. Shenbrot GI. Spatial structure and niche patterns of a rodent community in the south Bukhara desert (middle Asia). Ecography. 1992;15:347-57.

31. Alagaili AN, Mohammed OB, Bennett NC, Oosthuizen MK. A tale of two jirds: the locomotory activity patterns of king jird (Meriones rex) and Lybian jird (Meriones libycus) from Saudi Arabia. J Arid Environm. 2013;88:102-12.

32. Darvish J, Siahsarvie R, Mirshamsi O, Kayvanfar N, Hashemi N, et al. Diversity of the rodents of northeastern Iran. Iran J Animal Biosystem. 2006;2:57-76.

33. Himsworth CG, Jardine CM, Parsons KL, Feng AYT, Patrick DM. The characteristics of wild rat (Rattus spp.) populations from an inner-city neighborhood with a focus on factors critical to the understanding of rat-associated zoonoses. PLoS One. 2014:9:e91654.

34. Cavia R, Cueto GR, Suárez OV. Changes in rodent communities according to the landscape structure in an urban ecosystem. Landscape Urban Plan. 2009;90:11-9.

35. Boursot P, Auffray JC, Britton-Davidian J, Bonhomme F. The evolution of house mice. Annu Rev Ecol Syst. 1993:24:119-52.

36. Hamid HS, Darvish J, Rastegar-Pouyani E, Mahmoudi A. Subspecies differentiation of the house mouse Mus musculus Linnaeus, 1758 in the center and east of the Iranian plateau and Afghanistan. Mammalia. 2017:81:147-68.

37. Adhikari $\mathrm{P}$, Han S-H, Kim Y-K, Kim T-W, Thapa TB, Subedi N, Adhikari P, Oh $\mathrm{H}$-S. First molecular evidence of Mus musculus bactrianus in Nepal inferred from the mitochondrial DNA cytochrome B gene sequences. Mitochondrial DNA Part A > DNA Mapping, Sequencing, and Analysis. 2017; doi:10.1080/ 24701394.2017.1320994

38. Guénet J-L, Bonhomme F. Wild mice: an ever-increasing contribution to a popular mammalian model. TIG. 2003;19:24-31.

39. Hardouin EA, Orth A, Teschke M, Darvish J, Tautz D, Bonhomme F. Eurasian house mouse (Mus musculus L.) differentiation at microsatellite loci identifies the Iranian plateau as a phylogeographic hotspot. BMC Evol Biol. 2015;15:26. doi:10.1186/s12862-015-0306.

40. Mikula O, Auffray J-C, Macholan M. Asymmetric size and shape variation in the central European transect across the house mouse hybrid zone: asymmetric variation in mouse hybrids. Biological J Linnean Soc. 2010;101:13-27.

41. Darvish J, Orth A, Bonhomme F. Genetic transition in the house mouse, Mus musculus of eastern Iranian plateau. Folia Zool. 2006:55:349-57.

42. Baird SJE, Macholán M. What can the Mus musculus musculus/M. m. domesticus hybrid zone tell us about speciation? In: Evolution of the house mouse. Cambridge, UK: Cambridge University Press; 2012. p. 334-61. 
43. Teeter KC, Payseur BA, Harris LW, et al. Genome-wide patterns of gene flow across a house mouse hybrid zone. Genome Res. 2008;18:67-76.

44. Turner LM, Schwahn DJ, Harr B. Reduced male fertility is common but highly variable in form and severity in a natural house mouse hybrid zone. Evolution. 2012;66:443-58.

45. Suzuki TA, Nachman MW. Speciation and reduced hybrid female fertility in house mice. Evolution. 2015;69:2468-81.

46. Prager EM, Orrego C, Sage RD. Genetic variation and phylogeography of central Asian and other house mice, including a major new mitochondrial lineage in Yemen. Genetics. 1998;150(2):835-61.

47. Harr B, Karakoc E, Neme R, Teschke M, Pfeifle C, Pezer Ž, Babiker H, Linnenbrink M, Montero I, Scavetta R, Reza Abai M, Puente Molins M, Schlegel M, Ulrich RG, Altmüller J, Franitza M, Büntge A, Künzel S, Tautz D. Genomic resources for wild populations of the house mouse, Mus musculus and its close relative Mus spretus. Sci Data. 2016:3:160075.

48. Kjeldsberg E, Hem A. Detection of astroviruses in gut contents of nude and normal mice. Arch Viro. 1985;84:135-40.

49. Chu DK, Chin AW, Smith GJ, Chan KH, Guan Y, Peiris JS, Poon LL. Detection of novel astroviruses in urban brown rats and previously known astroviruses in humans. J Gen Virol. 2010;91:2457-62. doi:10.1099/vir.0.022764-0.

50. Ng TF, Kondov NO, Hayashimoto N, Uchida R, Cha Y, Beyer Al, Wong W, Pesavento PA, Suemizu H, Muench MO, Delwart E. Identification of an astrovirus commonly infecting laboratory mice in the US and Japan. PLoS One. 2010;8:E66937.

51. De Benedictis P, Schultz-Cherry S, Burnham A, Cattoli G. Astrovirus infections in humans and animals - molecular biology, genetic diversity, and interspecies transmissions. Inf Gen Evol. 2011;11:1529-44.

52. Parvizi P, Moradi G, Akbari G, Farahmand M, Ready PD, et al. PCR detection and sequencing of parasite ITS-rDNA gene from reservoir host of zoonotic cutaneous leishmaniasis in central Iran. Parasitol Res. 2008;103:1273-8.

53. Meerburg BG, Singleton GR, Kijlstra A. Rodent-borne diseases and their risks for public health. Crit Rev Microbiol. 2009;35:221-70.

\section{Submit your next manuscript to BioMed Central and we will help you at every step:}

- We accept pre-submission inquiries

- Our selector tool helps you to find the most relevant journal

- We provide round the clock customer support

- Convenient online submission

- Thorough peer review

- Inclusion in PubMed and all major indexing services

- Maximum visibility for your research

Submit your manuscript at www.biomedcentral.com/submit

) Biomed Central 